\title{
Report calls for shift in climate research
}

\section{Federal agencies must make climate research more applicable to end-users, says the US National Research Council. Mark Schrope reports.}

T he US government's climate research needs a radical refocus to make its results more relevant to policymakers and other stakeholders. That will require more interdisciplinary research and better understanding of the effects of climate change on local scales, says a new report ${ }^{1}$ released 26 February by the National Research Council (NRC), the policy-advice arm of the US National Academy of Sciences.

"Robust and effective responses to climate change demand a vastly improved body of scientific knowledge," says the NRC committee in its report Restructuring Federal Climate Research to Meet the Challenges of Climate Change. The 16-member committee was charged with evaluating the US Climate Change Science Program (CCSP), an umbrella entity that coordinates nearly $\$ 2$ billion in annual climate change work within US government agencies.

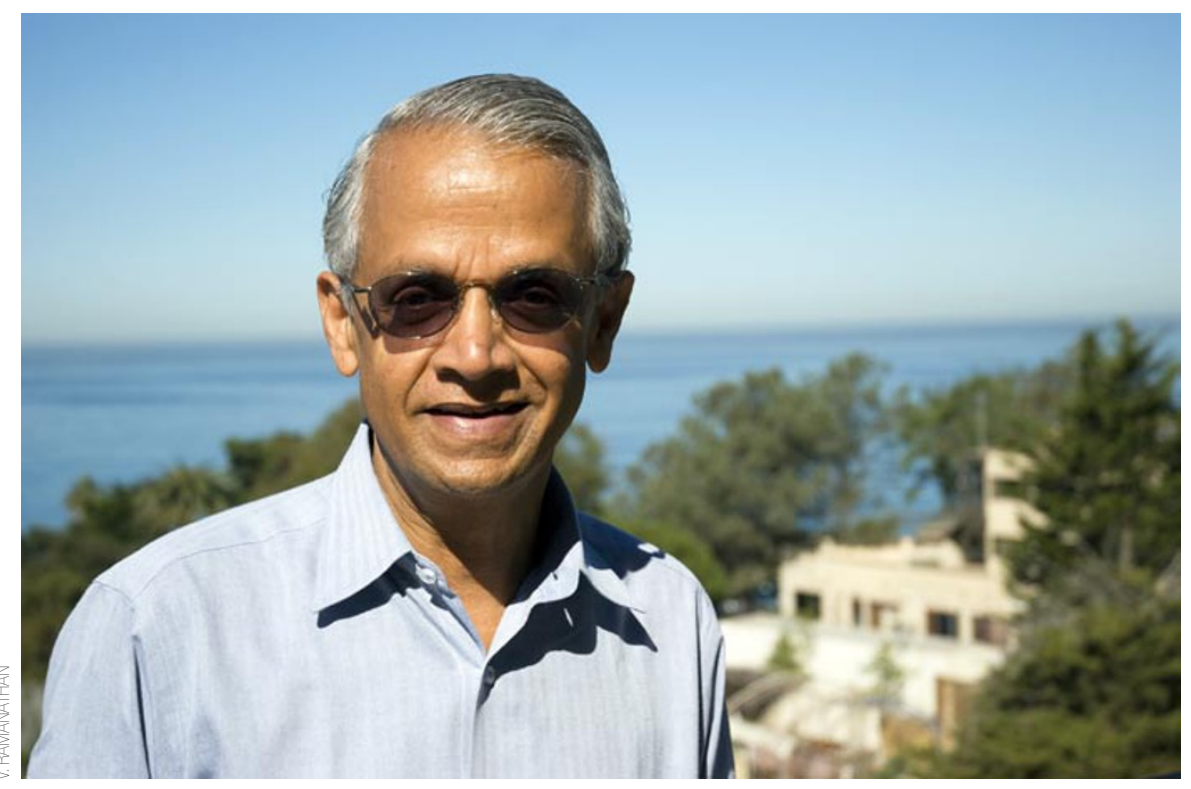

"we're just at the beginning of developing the capability to deliver that science so it can be used in society."

States will need a comprehensive climate observing system, improved modelling capabilities and further collaboration between physical and social scientists, says the committee. The report arrives at a critical time, with the CCSP currently developing a new strategic plan. Though the degree to which the recommendations will be acted on is not yet clear, initial responses from the climate science community have been positive.

"It's encouraging that people recognize our science has reached a threshold where we know what the problem is at the broad scale and have good insight as to how to deal with it," says Jonathan Overpeck, a climate scientist at the University of Arizona in Tucson and a coordinating lead author of the most recent Intergovernmental Panel on Climate Change (IPCC) assessment. But, he says,

\section{"We are saying that we should refocus the program around societal issues. It's going to take, I would say, quite a revolutionary approach."}

Veerabhadran Ramanathan

"In the long run I think this report will prove to be exceedingly useful," says Jack Kaye, acting chair of the CCSP's subcommittee on global-change research and the associate director for research at NASA's Earth Science Division, based in Washington DC.

\section{SOCIAL SUPPORT}

One of the report's recommendations is that climate research should be designed from the outset to address the needs of society rather than being driven by the unanswered questions in science. "We are saying that we should refocus the program around societal issues," says Veerabhadran Ramanathan, a climate scientist at the Scripps Institution of Oceanography in La Jolla, California, and chair of the report committee. "It's going to take, I would say, quite a revolutionary approach."

Among other changes, this will require more research into how humans affect and are affected by climate. Topics could include, for example, the factors that induce migration or the extent of air-conditioner use in various regions. Overpeck says that attention to the social side of climate change, which to date has received a paltry three per cent of the CCSP budget, has been "anemic", and that even modest new investment could yield major positive results. 
But that's not to suggest that the basic physics, biology and chemistry driving climate change are adequately understood, says Ramanathan. "Our report is pretty clear that the basic science is the foundation we have to build on," he says. Chris Field, an ecologist at the Carnegie Institution in Stanford, California, and a newly elected co-chair of the IPCC's Working Group II, says that in the past it has been difficult to align the results of research from different disciplines because each was essentially setting its own agenda. Field concedes that an increased focus on applications can cause too much of a shift away from curiosity-driven research, but "maintaining the right balance is always a big challenge," he says.

Another key issue will be getting the relevant information across to policymakers and other stakeholders in a form they can use. To that end, the report supports establishing a National Climate Service distinct from the CCSP. The National Oceanic and Atmospheric Administration (NOAA) is in the process of developing such a body to provide local and national officials with information about climate impacts such as drought and sea level rise on a timescale of months or years ${ }^{2}$. Further details have not yet been announced.

\section{COSTLY CHANGES}

But realizing the report's full vision will carry substantial costs. Recognizing that questions about climate change remain unanswered, the report calls on US agencies such as NOAA and the Environmental Protection Agency to plan for establishing a comprehensive climate observing system to bring in new data. That will require financing crucial operations such as satellite missions to measure changes in soil moisture and in the height of ice sheets. "We're actually looking at a future of decreasing capabilities from satellite observations, and it represents a crisis," says Field. In addition, increased financial support will be needed to boost computing power to enable climate projections at smaller spatial scales and to build an emerging generation of Earthsystem models, which should improve understanding of biological impacts on climate. "I think the recommendations are very appropriate and much needed," says Overpeck, "but it seems completely unrealistic to me that we could provide decision-makers with what they need with the current budget. It's just too small."

But in spite of the budget-threatening effects of the worst economic downturn since the Great Depression, government research stands to benefit from the US economic stimulus package. The package includes enough funding for agencies to begin addressing some of the report's recommendations. Some $\$ 170$ million has been apportioned for climate change research at NOAA, and $\$ 400$ million has been set aside to accelerate missions recommended in another recent NRC report, Earth Science and Applications from Space, which identified pressing needs for climate observations. Moreover, in the proposed \$3.6-trillion budget for fiscal year 2010, President Obama has planned an increase in NASA's budget from $\$ 17.8$ billion to $\$ 18.7$ billion, with an emphasis on global climate-monitoring missions, and has proposed allocating another $\$ 1.3$ billion specifically to NOAA, in part for climate sensors ${ }^{3}$.

"The recommendations are very appropriate, but it seems completely unrealistic that we could provide decision makers with what they need with the current budget. It's just too small."

Jonathan Overpeck

However, realizing anything approaching the report's full vision will undoubtedly require further capital. With a new administration, whether that will happen is an open question. "You could ask 100 scientists and they would give you an answer that was no more informed than 100 truck drivers," says Field with a laugh. "If the administration sticks with the goal of solutions to climate change as part of resolving the economic crisis, I think there's a decent chance." Overpeck agrees, "I think we can achieve the funding levels needed if we understand that we're talking about making the US a global leader in innovation on climate change."

\section{Published online: 26 March 2009}

\section{doi:10.1038/climate.2009.29}

\section{References}

1. Committee on Strategic Advice on the US Climate Change Science Program; National Research Council. Restructuring Federal Climate Research to Meet the Challenges of Climate Change (National Academies Press, 2009).

2. Kwok, R. Nature doi:10.1038/news.2009.108 (2009).

3. Hand, E. \& Wadman, M. Nature 458, 18 (2009).

Mark Schrope is a freelance science writer based in Florida.

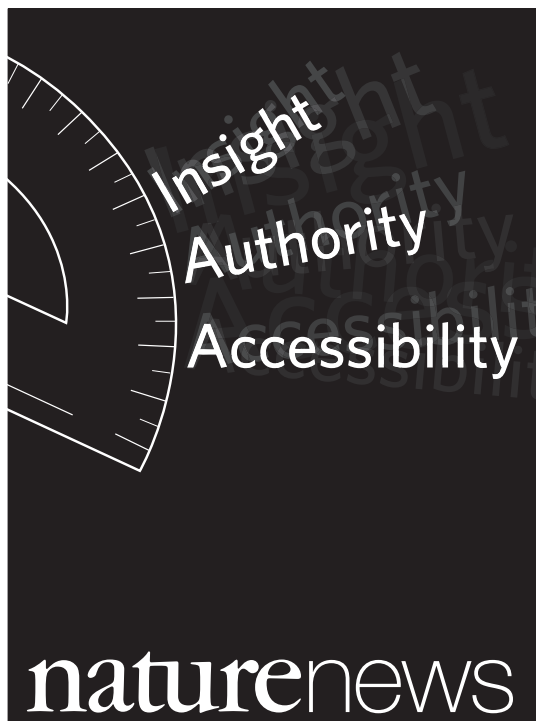

Science

news from

a different angle

From daily science

updates to investigative journalism, from community commentary to editorial opinions, Nature brings you the most in-depth science news coverage online.

www.nature.com/news

nature publishing group $\mathrm{npg}$ 